\title{
Partial characterization of galactosyltransferase in human seminal plasma and its distribution in the human epididymis
}

\author{
P. Ross ${ }^{1,2}$, N. Vigneault ${ }^{2}$, S. Provencher ${ }^{2}$, M. Potier ${ }^{3}$ and \\ K. D. Roberts ${ }^{1,2 *}$ \\ ${ }^{1}$ Department of Biochemistry, University of Montreal, ${ }^{2}$ Maisonnewve-Rosemont Hospital Research \\ Center and ${ }^{3}$ Medical Genetics Section, Sainte-Justine Hospital, Montréal, Québec, Canada
}

\begin{abstract}
Galactosyltransferase activity has been partially characterized in human seminal plasma. $K_{\mathrm{m}}$ values of $130 \mathrm{mmol} \mathrm{l}^{-1}$ for UDP-galactose and $2.25 \mathrm{mmol} \mathrm{l}^{-1}$ for $\mathrm{N}$-acetylglucosamine were calculated and the enzyme was found to be dependent on temperature and manganese and present as a highly active component of human seminal plasma. Galactosyltransferase was inhibited by nucleotides, glycosylated nucleotides, bovine and human $\alpha$-lactalbumin but not by monosaccharides. Radiation inactivation studies revealed that the biologically active unit of seminal plasma galactosyltransferase has a molecular mass of $45 \mathrm{kDa}$. Although the majority of galactosyltransferase activity found in seminal plasma is probably of prostatic origin, we report for the first time that it is also present in human epididymal intraluminal fluid. Low activity was detected in the proximal caput region but activity increased to maximum values in the adjacent downstream segment, the intermediate caput region. Specific activity was relatively constant albeit at a lower value in the following epididymal segments and vas deferens. The significance of the epididymal and seminal plasma galactosyltransferase activities is unknown, but the enzyme could be implicated in glycosylation events that are known to be important in gamete interaction.
\end{abstract}

\section{Introduction}

Mouse sperm membrane-bound $\beta$-1,4-galactosyltransferase (E.C. 2.4.1.38, GalTase) has been the subject of numerous studies, which have shown that this enzyme is involved in gamete interactions (Macek and Shur, 1988). A soluble form of GalTase in the male reproductive tract has also been described in rats (Hamilton, 1981) and mice (McLaughlin and Shur, 1987). GalTase is a member of the glycosyltransferase family responsible for the synthesis of complex substrates such as glycosaminoglycans, glycolipids and glycoproteins (see Strous, 1986, for review). Although it is principally found in the Golgi apparatus, plasma membrane-bound and soluble forms have also been described. The presence of GalTase on the plasma membrane of various cell types has been associated with its role in cell adhesion and cellular interaction (Shur, 1984). Accordingly, GalTase has been implicated in morula compaction in the mouse (Bayna et al., 1988), neural crest migration (Runyan et al, 1986), and infiltration of adrenal carcinoma (Penno et al., 1989) and melanoma cells (Passaniti and Hart, 1990). GalTase also plays a role in gamete interaction in mice (Macek and Shur, 1988). The enzyme is synthesized in the testis and gradually becomes localized on the plasma membrane overlying the acrosomal region of the spermatozoon (Scully et al., 1987). It has been shown to have an affinity for the zona pellucida (Lopez et al., 1985) and thus represents one of the components associated

*Reprint requests.

Received 8 June 1992. with gamete recognition (Benau and Storey, 1988). GalTase has also been detected on equine and bovine spermatozoa (FayrerHosken et al., 1991). Moreover, an immunologically reactive sperm protein has been detected using anti-GalTase antibodies on a population of human spermatozoa separated on a Percoll gradient (Sullivan et al., 1989). Humphreys-Beher et al. (1990) detected anti-GalTase antibodies in sera of patients with antisperm antibodies. Although some enzyme activity has been detected in human sperm cells (Humphreys-Beher and Blackwell, 1989; Humphreys-Beher et al., 1990; Miller et al., 1992), other investigators have been unable to detect significant GalTase activity associated with these cells (Tulsiani et al., 1990). The role of this immunologically reactive protein on human spermatozoa is unknown.

A soluble form of GalTase that can galactosylate a $26 \mathrm{kDa}$ sperm membrane protein has been described in the rat rete testis and epididymal fluids (Hamilton, 1981; Hamilton and Gould, 1982). It has also been detected in epididymal, prostatic and seminal vesicle cytosolic preparations in mice, hamsters and guinea pigs (Reddy et al., 1976) and in the intraluminal fluid of the mouse caput epididymis (McLaughlin and Shur, 1987). Tadolini et al. (1976) were the first to detect GalTase activity in human seminal plasma and they measured the enzyme activify in a membrane-free fraction as well as in fluid obtained after prostatic massage. However, no further characterization of the enzyme has since been undertaken. In this paper, we report the partial characterization of GalTase activity in human seminal plasma. In addition, epididymides obtained from cadavers were used to measure the enzyme activity in the intraluminal fluid 
obtained from the various epididymal regions. The possible role of this enzyme in seminal plasma and epididymal fluid is also discussed.

\section{Materials and Methods}

\section{Seminal plasma samples}

Frozen semen samples ( $1.1 \mathrm{l}$ ) collected in fertility clinics in the Montreal region were pooled and benzamidine hydrochloride was added to a final concentration of $50 \mathrm{mmol} \mathrm{l}^{-1}$. The pooled semen was centrifuged for $10 \mathrm{~min}$ at $600 \mathrm{~g}$ to remove spermatozoa and the supernatant was subsequently ultracentrifuged for $30 \mathrm{~min}$ at $100000 \mathrm{~g}$ to remove cellular debris. The seminal plasma was delipidated by precipitating the proteins by adding 8 volumes of $95 \%$ ethanol. The precipitate was left at $-4^{\circ} \mathrm{C}$ for $24 \mathrm{~h}$ and centrifuged for $20 \mathrm{~min}$ at $8000 \mathrm{~g}$ to obtain a protein pellet. After washing twice with $95 \%$ ethanol, the pellet was resuspended in $800 \mathrm{ml}$ water before being frozen and lyophilized. Half of this delipidated seminal plasma (DSP) was subsequently resuspended in a minimal volume and dialysed (cut-off of $12 \mathrm{kDa}$ ) against a $0.05 \mathrm{~mol}$ ammonium bicarbonate buffer $\mathrm{I}^{-1}(\mathrm{pH}$ 8.5). The dialysed and delipidated seminal plasma (DDSP) was subsequently frozen, lyophilized and aliquots were stored at $-20^{\circ} \mathrm{C}$.

\section{GalTase assay}

GalTase activity was measured according to Ram et al. (1989) with certain modifications. Samples were resuspended in the reaction buffer consisting of $120 \mathrm{mmol} \mathrm{NaCl} \mathrm{l}^{-1}, 4.8 \mathrm{mmol} \mathrm{KCl}$ $\mathrm{l}^{-1}, 1.7 \mathrm{mmol} \mathrm{CaCl} \mathrm{l}^{-1}, 1.2 \mathrm{mmol} \mathrm{MgCl}_{2} \mathrm{l}^{-1}, 10 \mathrm{mmol} \mathrm{MnCl}$ $1^{-1}$ and $25 \mathrm{mmol}$ Hepes $\mathrm{I}^{-1}$ at $\mathrm{pH} 7.2$. Four microlitres of this sample preparation was placed in a $0.5 \mathrm{ml}$ Eppendorf microcentrifuge tube and evaporated in a Speedvac (Savant Instruments, Farmingdale, NY). The reaction was started by the addition of approximately $0.3 \mu \mathrm{Ci}$ of UDP-[4,5- $\left.{ }^{3} \mathrm{H}\right]$ galactose (specific activity $0.8 \mathrm{Ci} \mathrm{mmol} \mathrm{^{-1 }}$ ), $23 \mathrm{mmol} N$-acetylglucosamine $\mathrm{I}^{-1}$ (GlcNAc) and $8 \mathrm{mmol}^{\prime}$-AMP $\mathrm{I}^{-1}$ in a total volume of $4 \mu \mathrm{l}$. The tubes were tightly closed and incubated for $30-120 \mathrm{~min}$ in a shaking water bath set at $37^{\circ} \mathrm{C}$. The reaction was stopped by adding $4 \mu \mathrm{l}$ of cold $50 \mathrm{mmol}$ EDTA I ${ }^{-1}$ and by placing the tubes on ice. A control tube containing the substrate but no enzyme was included in each assay to evaluate non-enzymatic degradation.

The presence of an endogenous acceptor of $\left[{ }^{3} \mathrm{H}\right]$ galactose was verified by incubating $4 \mu \mathrm{l}$ fractions of seminal plasma $(7 \mu \mathrm{g})$, DSP $(7 \mu \mathrm{g})$ or a commercial preparation of bovine milk galactosyl-transferase ( $\mathrm{Ing}$ ) (Sigma) in the presence or absence of exogenous GlcNAc $\left(23 \mathrm{mmol} \mathrm{l}^{-1}\right)$.

\section{Separation of the radiolabelled product}

Samples containing a final volume of $8 \mu \mathrm{l}$ were mixed in a $100 \mu \mathrm{l}$ Hamilton syringe with $50 \mu \mathrm{l}$ of methanol and applied to a $10 \times 20 \mathrm{~cm}$ polyethylenimine-cellulose thin layer chromatography plate using an automated sample applicator (Multi Spotter, AIS, Libertyville, IL). The plates were placed in a tank containing $1 \mathrm{mmol}$ sodium phosphate buffer $\mathrm{l}^{-1}(\mathrm{pH} \mathrm{8.0)}$ and following a $10 \mathrm{~cm}$ migration, the top $4.5 \mathrm{~cm}$ containing the radiolabelled product was scraped off and placed in a plastic vial to which $250 \mu \mathrm{l}$ of sodium phosphate buffer at $\mathrm{pH} 3.0$ was added to elute the product. The amount of $\left[{ }^{3} \mathrm{H}\right]$ galactose transferred was established by the addition of $10 \mathrm{ml}$ of scintillation fluid (P989, NEN Dupont, Mississauga, Ontario) and assay of the radioactivity in an LKB Model 1217 beta counter.

\section{Characterization of seminal plasma GalTase activity}

The Michaelis-Menten constants of seminal plasma GalTase were determined by solubilizing samples of DDSP $(7 \mu \mathrm{g})$ in $4 \mu \mathrm{l}$ of reaction buffer containig $5^{\prime}$-AMP and increasing amounts of GlcNAc $\left(0.4-50 \mathrm{mmol} \mathrm{I}^{-1}\right)$ or UDP-galactose $\left(1.7 \mu \mathrm{mol} \mathrm{l}^{-1}\right.$ $50 \mathrm{mmol} \mathrm{l}^{-1}$ ). After Speedvac evaporation of the sample, the reaction was started by adding the radiolabelled substrate. A one hour incubation time was used.

The effects of incubation for $90 \mathrm{~min}$ at different temperatures $\left(24,30,32,37,40\right.$ and $\left.45^{\circ} \mathrm{C}\right)$ or at $37^{\circ} \mathrm{C}$ with increasing amounts of manganese $\left(0,5,10,15,20,30\right.$ and $40 \mathrm{mmol} \mathrm{MnCl}_{2}$ $1^{-1}$ ) were also evaluated.

\section{Inhibition studies}

The specificity of glycosylation was evaluated by the addition of various substances some of which are known GalTase inhibitors. Nucleotides (UMP, UDP and UTP), glycosylated nucleotides (UDP-mannose and UDP-glucose) as well as monosaccharides ( $\beta$-D-glucose, D-galactose, D-mannose, myo-inositol, D-arabinose and $\alpha$-fucose) were added in concentrations varying from 0.5 to $50 \mathrm{mmol} \mathrm{l}^{-1}$ (in water) to dried samples of DDSP previously solubilized in the reaction buffer (final concentration was $7 \mu \mathrm{g}$ $\left.\mathrm{ml}^{-1}\right)$. Incubations were performed at $37^{\circ} \mathrm{C}$ for $90 \mathrm{~min}$. The effect of increasing concentrations of bovine (Sigma) and human (Sigma) $\alpha$-lactalbumin as well as BSA (Sigma) were also tested using the same experimental conditions.

\section{Radiation inactivation studies}

Radiation inactivation studies can be used to estimate the radiation inactivation size (RIS) of an enzyme which corresponds to the biologically active unit of the enzyme (Beauregard et al., 1987). The advantage of this technique is that it can be used on crude preparations of the particular enzyme under study. Aliquots of DDSP ( $7 \mu \mathrm{g} \mathrm{ml}^{-1}$ reaction buffer) were dried and kept at $-80^{\circ} \mathrm{C}$ in $0.5 \mathrm{ml}$ Eppendorf centrifuge tubes. The air in the tubes was evacuated by a gentle stream of nitrogen and the samples were subsequently placed in a ${ }^{60} \mathrm{Co}$ irradiator (Gammacell, model 220, Atomic Energy of Canada). Samples were submitted to irradiation times of $0,1,2,3,4.5,6,7.5$, 9, 10.5 and $12 \mathrm{~h}$ corresponding to increasing radiation doses. Triplicate samples were irradiated for each dose and the experiment was repeated twice. The enzymatic activity was measured by adding the radiolabelled substrate as mentioned above using a $2 \mathrm{~h}$ incubation time at $37^{\circ} \mathrm{C}$.

\section{Epididymal samples}

Epididymides were obtained from two 36-year-old male subjects in an organ donor programme within $4 \mathrm{~h}$ of death and 


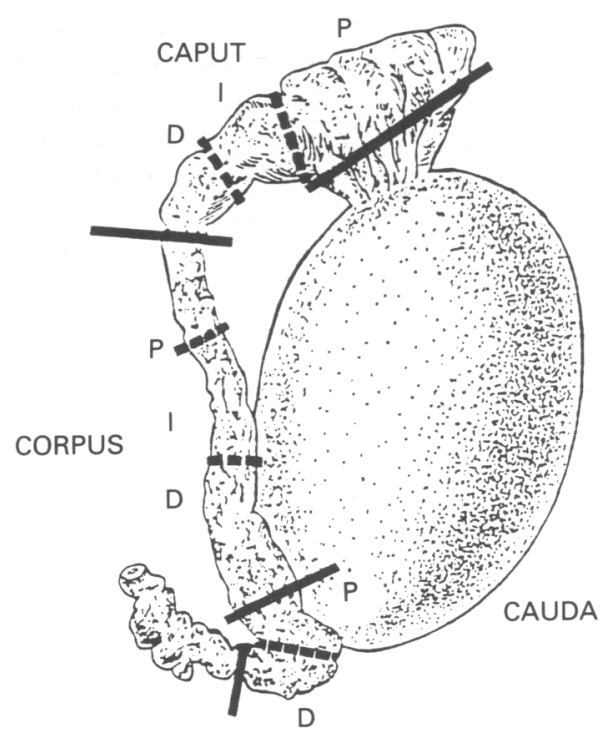

Fig. 1. Schematic drawing of the human epididymis representing the different regions from which intraluminal fluid was collected. P: proximal; I: intermediate; and D: distal regions of the caput and corpus epididymis. (Redrawn from Baumgarten et al., 1971.)

were kept on ice. The various regions of the caput and corpus epididymides (see Fig. 1) were punctured with a fine needle and a capillary was placed in the opening to collect intraluminal fluid. The epididymis was not dissected into the different segments to maintain a certain tonicity which facilitated fluid expulsion. Samples from the cauda and vas deferens were obtained by flushing the tubule lightly with $200 \mu \mathrm{l}$ of reaction buffer through a small calibre syringe. The fluids of the epididymis and vas deferens were centrifuged $(3000 \mathrm{~g}, 15 \mathrm{~min})$ to remove spermatozoa and further ultracentrifuged $(100000 \mathrm{~g}$, $30 \mathrm{~min}$ ) to eliminate particulate matter. Protein determinations were measured using the method of Bradford (1976). GalTase assay was achieved by evaporating $4 \mu \mathrm{l}$ tubular fluid from the assay tubes and by the addition of reaction buffer containing the radiolabelled substrate and the acceptor followed by incubation as described above.

\section{Spermatozoa}

Fresh spermatozoa were obtained from two healthy donors and the volume was completed to $10 \mathrm{ml}$ with the reaction buffer. After removing the seminal plasma by centrifugation $(600 \mathrm{~g}, 10 \mathrm{~min})$, the sperm cells were washed twice with $10 \mathrm{ml}$ of reaction buffer and recentrifuged. The final pellet was resuspended in $5 \mathrm{ml}$ of reaction buffer, the sperm cells were counted, separated into increasing amounts, and dried in the assay tubes. The enzymatic reaction was performed as described above. The sperm membranes have been shown to remain intact using this technique as we have described (Langlais et al., 1981).

GalTase activity was also measured in murine spermatozoa. After killing the mice by cervical dislocation, the epididymides were dissected free and the caudal segments were punctured in a Petri dish containing reaction buffer. The spermatozoa were collected, washed and processed as described for human ejaculated spermatozoa.

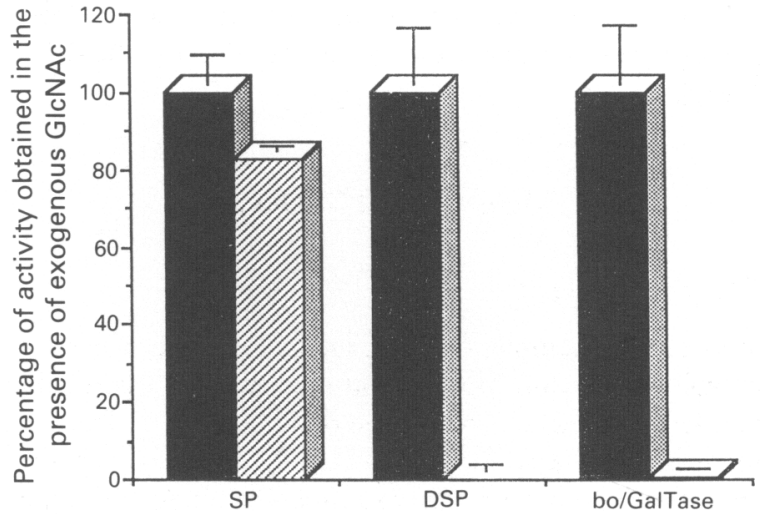

Fig. 2. Galactosyltransferase activity in the presence ( $\boldsymbol{\square})$ and absence (Ø) of exogenous $N$-acetylglucosamine (GlcNAc). Seminal plasma (SP), delipidated seminal plasma (DSP), and bovine milk galactosyltransferase (bo/GalTase) were incubated for $1 \mathrm{~h}$ at $37^{\circ} \mathrm{C}$ in the presence and absence of $23 \mathrm{mmol}$ GlcNAc $\mathrm{l}^{-1}$. Activities obtained in the presence of exogenous GlcNAc are fixed at $100 \%$ activity, and the values obtained in the absence of GlcNAc were calculated as a percentage of activity relative to this.

\section{Results}

\section{GalTase assay}

The thin layer chromatography method used in these experiments separates sugar nucleotides which remain at the origin from glycosylated acceptors (Ram et al., 1989). The reaction product is separated from the radiolabelled substrate and can be removed by scraping off the top $4.5 \mathrm{~cm}$ of the polyethylenimine-cellulose plate. GalTase activity is present in human seminal plasma (Fig. 2) and this activity is located in the protein pellet after precipitation. However, a galactose acceptor is lost in the latter step as demonstrated by the fact that, in seminal plasma, $83 \%$ of the enzyme activity is obtained in the absence of exogenous GlcNAc, whereas no product was formed when DPS or bovine milk GalTase were used as enzyme sources and GlcNAc was deleted (Fig. 2). GalTase activity was linear with time and non-enzymatic degradation of the radiolabelled substrate was low and represented only $4 \%$ of the total radioactivity migrating with the thin layer chromatography buffer after a $120 \mathrm{~min}$ incubation. This non-enzymatic degradation was evaluated in each assay and was subtracted from those values obtained in the presence of enzyme.

\section{Kinetic analysis of GalTase activity}

Seminal plasma GalTase activity was temperature dependent (Fig. 3). The activity increased from 24 to $40^{\circ} \mathrm{C}$ (from $37 \%$ to $100 \%$, respectively), after which it decreased to approximately $80 \%$ of its maximum activity at $45^{\circ} \mathrm{C}$. Bovine milk GalTase exhibited a slightly different pattern with maximal activity occurring between 24 and $40^{\circ} \mathrm{C}$, to decrease subsequently by $30 \%$ at $45^{\circ} \mathrm{C}$.

Activity was low in the absence of manganese but increased when $5 \mathrm{mmol}$ manganese $\mathrm{l}^{-1}$ was added (Fig. 4). A plateau was obtained with a slight increase at concentrations varying from 20 to $40 \mathrm{mmol} \mathrm{l}^{-1}$. 


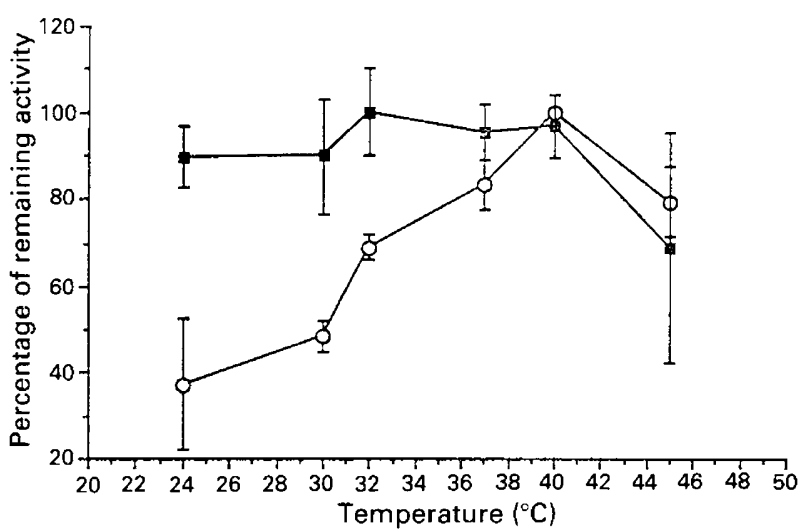

Fig. 3. Galactosyltransferase activity was calculated after a $90 \mathrm{~min}$ incubation at $24,30,32,37,40$ and $45^{\circ} \mathrm{C}$. Assays were done in triplicate and are expressed as percentages of the activity obtained at optimal temperature $\left(32^{\circ} \mathrm{C}\right.$ for bovine milk galactosyltransferase ( $\left.\boldsymbol{\square}\right)$ and $40^{\circ} \mathrm{C}$ for dialysed and delipidated seminal plasma $(\mathrm{O})$.

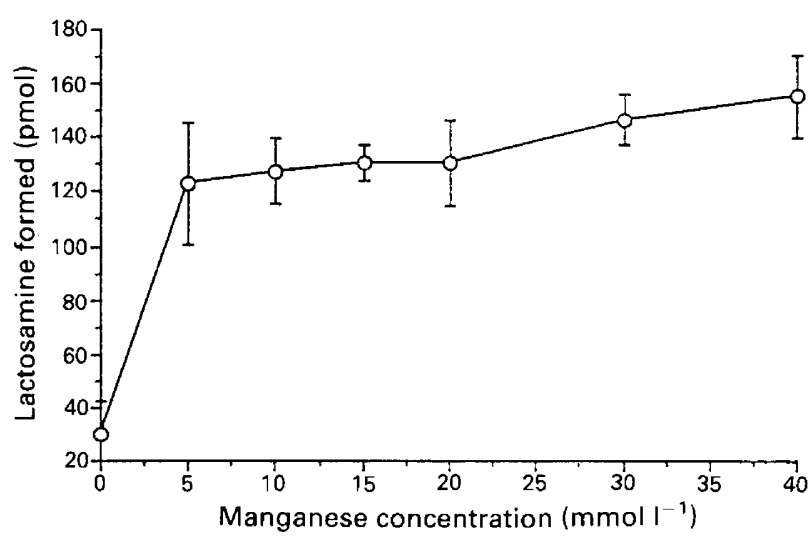

Fig. 4. Dialysed and delipidated seminal plasma was incubated for $90 \mathrm{~min}$ with increasing amounts of manganese and the amount of lactosamine formed was then measured.

When GalTase activity was calculated in the presence of different UDP-galactose concentrations, a $K_{\mathrm{m}}$ value of $130 \mu \mathrm{mol}$ $\mathrm{I}^{-1}$ and a $V_{\max }$ value of $148 \mathrm{pmol} \mathrm{h}^{-1}$ was obtained by plotting the Lineweaver-Burke double-reciprocal curve (Fig. 5a). Similarly, a $K_{\mathrm{m}}$ value of $2.25 \mathrm{mmol}^{-1}$ was calculated when GlcNAc concentrations were increased (Fig. 5b).

\section{Specificity studies}

The transfer of radiolabelled galactose was inhibited by the addition of several glycosylated products to the reaction mixture. The order of decreasing inhibition capability was UDP-mannose $\left(\mathrm{IC}_{50}\right.$ of $\left.0.02 \mathrm{mmol} \mathrm{l}^{-1}\right)$ and UDP-glucose $\left(\mathrm{IC}_{50}\right.$ of $1 \mathrm{mmol} \mathrm{l}^{-1}$ ) (Fig. 6a). Enzyme activity was also inhibited by the presence of uridine mono-, bi- and triphosphates (Fig. 6b). Uridine bi- and triphosphate produced a comparable effect $\left(\mathrm{IC}_{50}\right.$ of $0.04 \mathrm{mmol} \mathrm{l}^{-1}$ and $0.06 \mathrm{mmol} \mathrm{l}^{-1}$, respectively), whereas $\mathrm{UMP}$ was less potent $\left(\mathrm{IC}_{50}\right.$ of $\left.0.6 \mathrm{mmol} \mathrm{l^{-1 }}\right)$. Galactose, glucose, mannose, inositol, arabinose and fucose did not inhibit

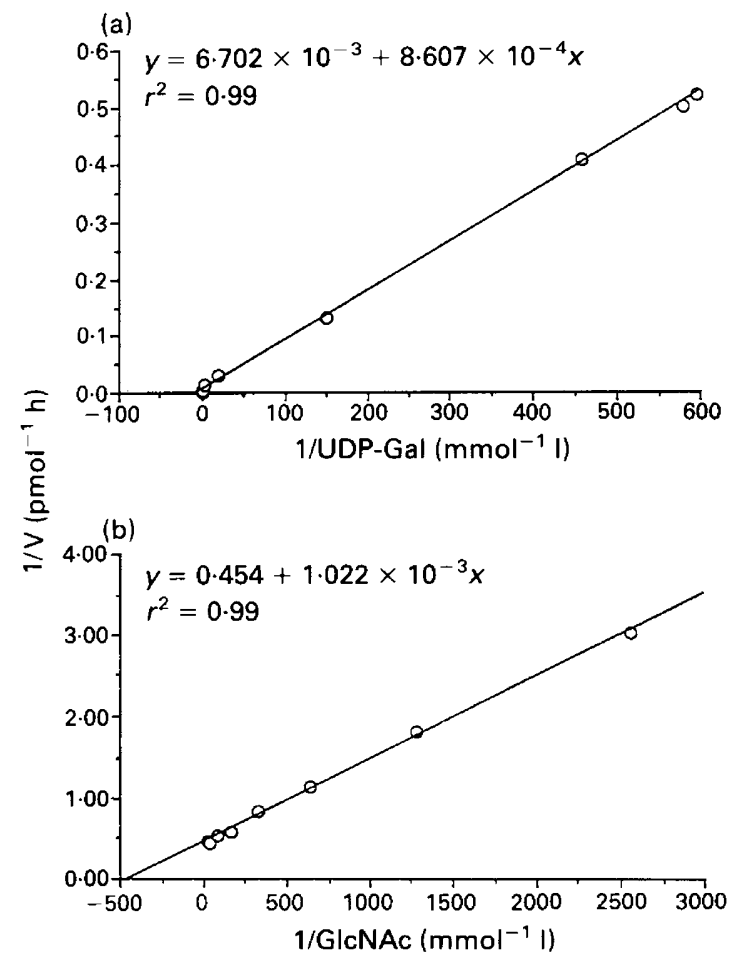

Fig. 5. Determination of Michaelis-Menten constants for (a) uridine diphosphate galactose (UDP-Gal) and (b) GlcNAc. Lineweaver-Burke double reciprocal curves of dialysed and delipidated seminal plasma galactosyltransferase activity measured in the presence of increasing amounts of (a) (UDP-Gal) or (b) $\mathrm{N}$-acetyl glucosamine are presented. The $K_{\mathrm{m}}$ values obtained from the curves were $130 \mu \mathrm{mol} 1^{-1}$ for uridine diphosphate galactose and $2.25 \mathrm{mmol}^{-1}$ for $\mathrm{N}$-acetyl glucosamine.

$\left[{ }^{3} \mathrm{H}\right]$ galactose transfer to GlcNAc at concentrations varying from $0.5 \mu \mathrm{mol} \mathrm{l}^{-1}$ to $100 \mathrm{mmol} \mathrm{l}^{-1}$ (Fig. $6 \mathrm{c}$ ).

The addition of $\alpha$-lactalbumin to the reaction mixture inhibited GalTase activity in a dose-dependent manner (Fig. 7). This inhibition was very similar whether human or bovine $\alpha$-lactalbumin was used. The $\mathrm{IC}_{50}$ value was $0.1 \%(4 \mu \mathrm{g}$ per assay) in both cases and total inhibition was achieved at a concentration of $1 \%$. However, BSA had no effect on activity at similar concentrations.

\section{Radiation inactivation studies}

The radiation inactivation size (RIS) of seminal plasma GalTase was determined by calculating the residual GalTase activity in DDPS samples placed in a calibrated ${ }^{60} \mathrm{Co}$ Gammacell (Beauregard and Potier, 1982). RIS can be defined as the mass of one mole of protein which loses its biological activity when hit by a single ionizing radiation. This entity is based on Lea's (1955) target theory whereby the probability of a molecule being hit by an ionizing radiation increases with its size for any given dose. The RIS can thus be calculated by plotting the relative initial enzyme activity of a protein as a function of the irradiation dose on a semi-logarithmic scale (Beauregard et al., 1987). The log of residual activity remaining following increasing radiation doses is shown (Fig. 8a). The enzymatic activity corresponding to a radiation dose of zero $\left(A_{0}\right)$ was extrapolated 
(a)
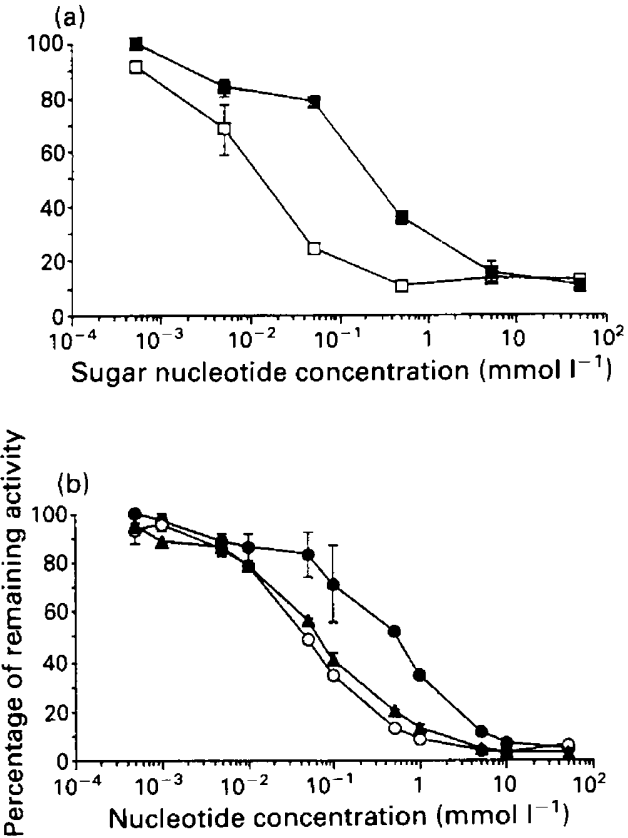

(c)

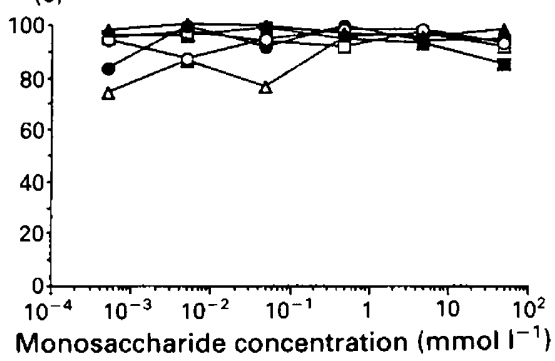

Fig. 6. Inhibition of seminal plasma galactosyltransferase activity with (a) sugar nucleotides, (b) nucleotides and (c) monosaccharides. Uridine diphosphate- $\left[{ }^{3} \mathrm{H}\right]$ galactose transfer to $\mathrm{N}$-acetyl galactose was assayed in the presence of increasing amounts of the different components. The percentage of remaining activity refers to the amount of enzyme activity obtained in the presence of the inhibitor relative to that obtained in its absence. Concentrations required to inhibit $50 \%$ of the maximal activity $\left(\mathrm{IC}_{50}\right)$ were, in (a) $0.02 \mathrm{mmol} \mathrm{l}^{-1}$ (uridine diphosphate

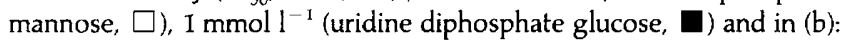
$0.6 \mathrm{mmol} \mathrm{I}^{-1}$ (uridine monophosphate, ), $0.04 \mathrm{mmol} \mathrm{l}^{-1}$ (uridine diphosphate, O) and $0.06 \mathrm{mmol} 1^{-1}$ (uridine triphosphate, $\mathbf{\Delta}$ ). As shown in (c) galactose $(\triangle)$, glucose $(\boldsymbol{\square})$, mannose $(\square)$, inositol $(\boldsymbol{Q})$, arabinose $(O)$ and fucose $(\boldsymbol{\Delta})$ did not inhibit the enzymatic reaction.

from the linear regression curve. The antilog of this value corresponds to $100 \%$ activity $\left(A_{\mathrm{o}}=1.603\right)$. On the basis of this value the residual activity obtained at each irradiation dose was calculated as a percentage of the initial activity and after log transformation (Fig. 8b). From this graph, it was calculated that, at $37 \%$ of the initial activity, this corresponds to an irradiation dose $\left(D_{37}\right)$ of 14.2 Mrad. Kepner and Macey (1968) have determined, empirically, a factor that is inversely proportional to the molecular mass of a biologically active protein and its $D_{37}$ :

$$
M_{\mathrm{r}}=\frac{6.4 \times 10^{5}}{D_{37}}
$$

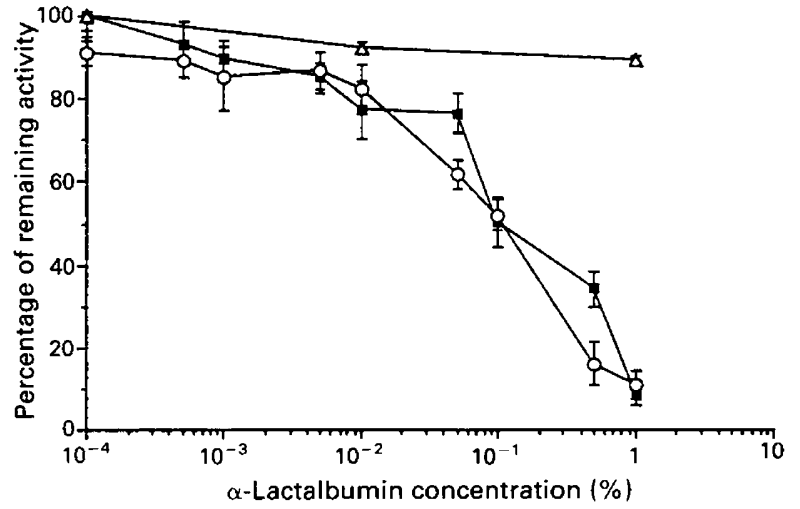

Fig. 7. Inhibition of seminal plasma galactosyltransferase activity by bovine and human $\alpha$-lactalbumin. Increasing amounts of bovine $(O)$, and human ( $\boldsymbol{a}) \boldsymbol{\alpha}$-lactalbumin were added to assays containing dialysed and delipidated seminal plasma. Residual activity (as a percentage) was calculated after $90 \mathrm{~min}$ of incubation at $37^{\circ} \mathrm{C}$. As controls, $0.0001,0.1$ and $1 \%$ albumin were also assayed in the presence of dialysed and delipidated seminal plasma $(\triangle)$.

(a)

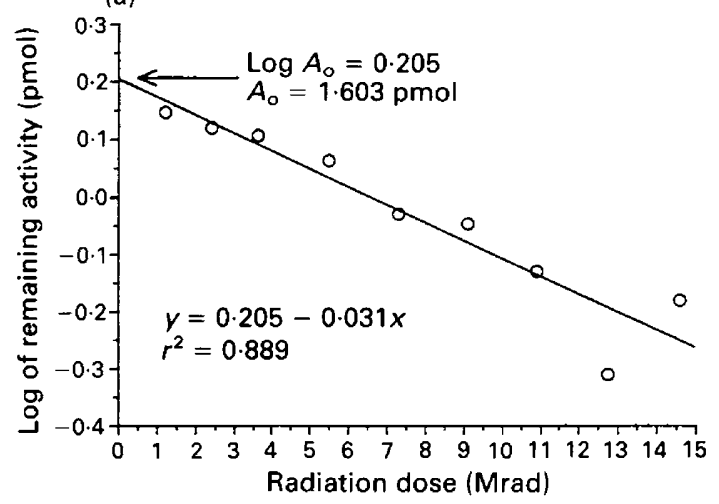

(b)

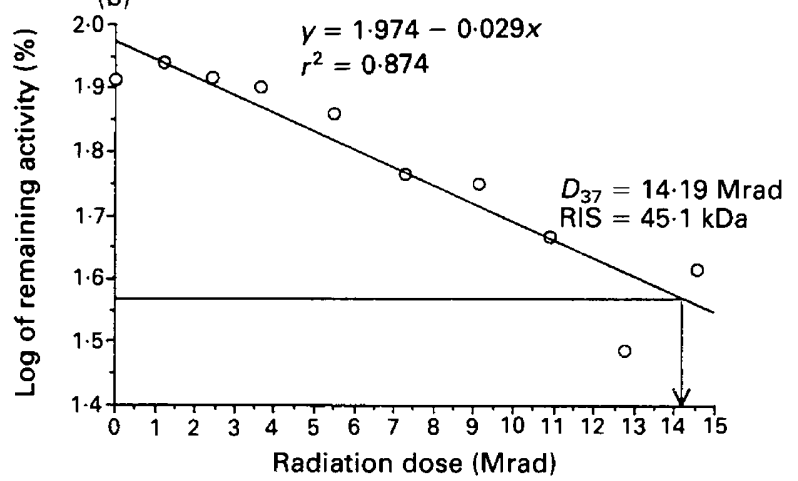

Fig. 8. Radiation inactivation studies. (a) The log of residual activity as a function of radiation dose is presented. Galactosyltransferase activity decreases with increasing radiation dose. By extrapolating the value obtained at a dose of $0 \mathrm{Mrad}$, the value corresponding to $100 \%$ activity $\left(A_{0}=1.603\right)$ can be estimated. (b) From the value obtained for $A_{0}(100 \%$ activity), the percentage of residual activity was calculated as a function of the radiation dose. At $37 \%$ of the initial activity $(Y=1.568)$, a radiation dose of $14.2 \mathrm{mRad}$ was obtained which corresponds to a radiation inactivation size (RIS) of $45 \mathrm{kDa}$. 


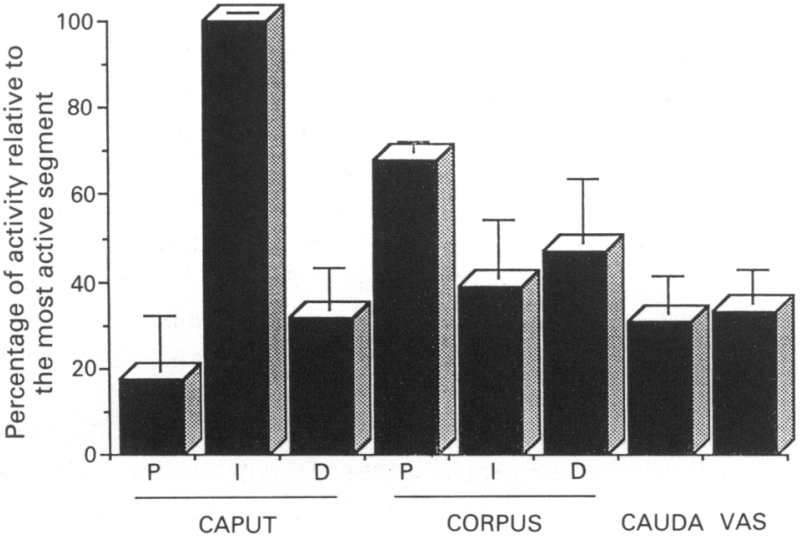

Fig. 9. The relative activity of galactosyltransferase in the human epididymis and vas deferens. Samples of intraluminal fluid obtained from two subjects were assayed for $2 \mathrm{~h}$ at $37^{\circ} \mathrm{C}$. Pooled duplicate measurements obtained with tissues from both subjects are represented. The activity is expressed as a percentage relative to the most active segment in each subject (intermediate region of the caput) (mean \pm SD). P: proximal; I: intermediate; and D: distal regions of the caput and corpus epididymis.

This equation is commonly used to calculate the RIS of an enzyme (Beauregard et al., 1987). The RIS value of GalTase can thus be calculated:

$$
\mathrm{RIS}=\frac{6.4 \times 10^{5}}{D_{37}}=\frac{6.4 \times 10^{5}}{14.2}=45.1 \mathrm{kDa}
$$

The mean value of RIS calculated from two radiation inactivation experiments was $44.8 \mathrm{kDa}$.

\section{GalTase activity in the intraluminal fluids of the epididymis and vas deferens}

Epididymal fluid was also studied for its ability to transfer $\left[{ }^{3} \mathrm{H}\right]$ galactose from UDP- $\left.{ }^{3} \mathrm{H}\right] \mathrm{Gal}$ to GlcNAc (Fig. 9). The specific GalTase activity present in the proximal caput region was low (0.17 pmol h${ }^{-1} \mu \mathrm{g}^{-1}$ of protein) but was found to increase in the following segment, the intermediate caput region, where it attained the highest specific activity $\left(3.94 \mathrm{pmol} \mathrm{h}^{-1} \mu \mathrm{g}^{-1}\right.$ protein) that was measured in the epididymis and vas deferens. The activity measured in downstream segments was lower and represented between $30 \%$ (cauda) and $67 \%$ (proximal corpus) of that obtained in the intermediate region of the caput. GalTase activity was maintained in the vas deferens where $1.30 \mathrm{pmol}$ $\mathrm{h}^{-1} \mu \mathrm{g}^{-1}$ of protein were transferred to GlcNAc.

\section{Human and mouse sperm GalTase activity}

Only slight activity was detected when human washed ejaculated spermatozoa were added to the reaction buffer (Fig. 10a). Even at concentrations of up to 100000 spermatozoa per assay, only $0.05 \pm 0.02 \mathrm{pmol} \mathrm{h}^{-1}$ of $\left[{ }^{3} \mathrm{H}\right]$ galactose were transferred to GlcNAc. However, for purposes of comparison, mouse
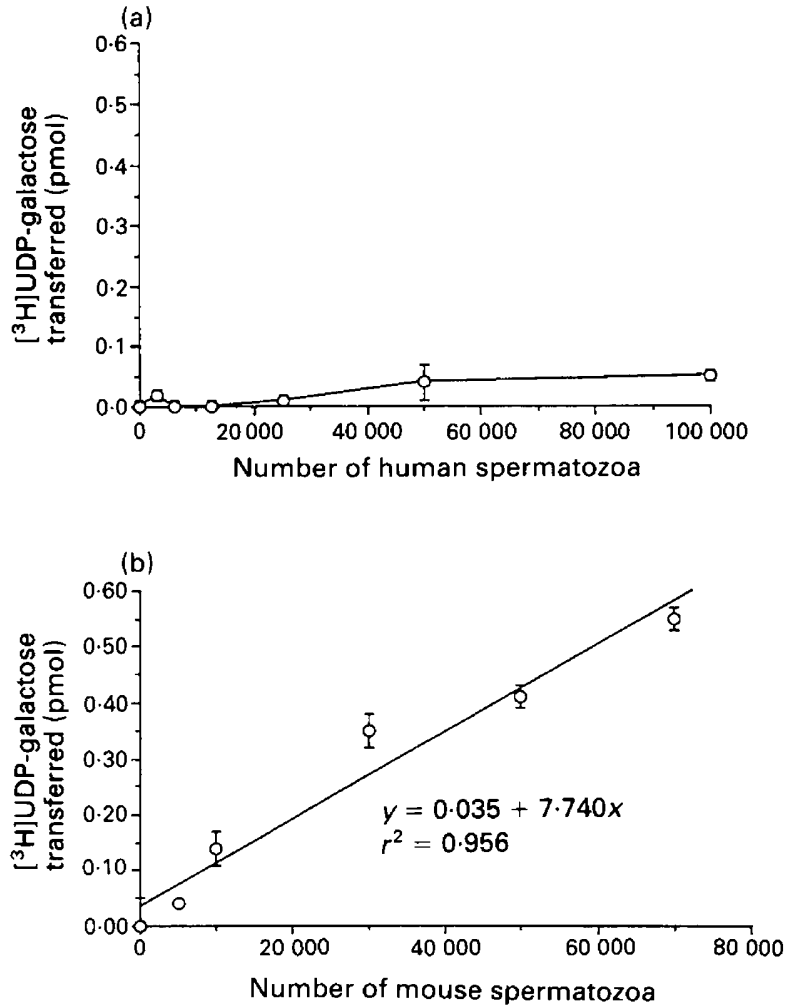

Fig. 10. Human and murine sperm galactosyltransferase activity as a function of number of spermatozoa. Samples containing increasing amounts of (a) human ejaculated and (b) murine caudal epididymal spermatozoa were assayed for galactosyltransferase activity. Values represent means \pm SD of duplicate experiments.

caudal sperm display GalTase activity that increased with sperm concentration (Fig. 10b).

\section{Discussion}

It is well known that GalTase participates in sperm-egg interaction in mice (Macek and Shur, 1988). As an immunologically reactive sperm membrane protein was detected on human spermatozoa using anti-GalTase antibodies (Sullivan et al., 1989), we proceeded to verify further the presence of GalTase on human spermatozoa using a more direct assay, i.e. via its enzymatic activity. Very low activity was found to be associated with human ejaculated spermatozoa, whereas much higher activity was found in the seminal plasma. The low enzymatic activity associated with spermatozoa is not related to the technique used since mouse spermatozoa exhibited GalTase activity using the same procedure. Other groups have also reported very little GalTase activity associated with human spermatozoa (Tadolini et al., 1976; Tulsiani et al., 1990). This minimal activity, as well as that described in this study, is possibly due to a contamination by the seminal plasma enzyme. Miller et al. (1992) found that some activity was associated with human spermatozoa, although it was approximately 15 -fold less than the activity previously measured with mouse spermatozoa using the same experimental conditions (Shur and Neely, 1988). 
The physiological significance of this activity thus remains to be clarified.

In agreement with the presence of an immunologically reactive protein similar to GalTase, Humphreys-Beher et al. (1990) reported the presence of anti-GalTase antibodies in the serum of infertile patients displaying anti-sperm antibodies. Moreover, they also provided evidence that certain patients whose spermatozoa were unable to fertilize zona-free hamster eggs have altered restriction patterns in their GalTase coding gene (Humphreys-Beher and Blackwell, 1989). Hence, an immunologically reactive form of GalTase that is devoid of activity may be present in human sperm membranes or this activity is inhibited in a manner that is not reversed by our experimental conditions. This phenomenon is similar to the trypsin inhibitor binding site on mouse spermatozoa which also does not possess catalytic activity (Aarons et al., 1984).

Seminal plasma is a rich source of GalTase. As shown by the kinetic analysis, its activity is linear up to $2 \mathrm{~h}$ and it depends upon the presence of manganese, which is in agreement with all GalTases that have been characterized (Strous, 1986). The $K_{m}$

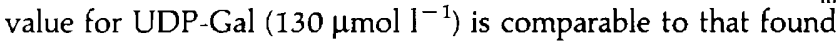
for GalTase in the epididymal fluid of the rat $\left(100 \mu \mathrm{mol} 1^{-1}\right.$; Hamilton, 1980) and mouse spermatozoa (30 $\mu \mathrm{mol} \mathrm{l}^{-1}$; Shur and Neely, 1988). The $K_{\mathrm{m}}$ value of the enzyme for GlcNAc $\left(2.25 \mathrm{mmol} \mathrm{l}^{-1}\right)$ is similar to that found on mouse spermatozoa (4 mmol $\mathrm{l}^{-1}$; Shur and Neely, 1988). The enzyme activity is temperature dependent. Activity increased between 24 and $40^{\circ} \mathrm{C}$ and subsequently decreased at $45^{\circ} \mathrm{C}$. This dependency on temperature is similar to that observed for intact mouse sperm GalTase but different from the purified form of this enzyme (Shur and Neely, 1988). A different dependence on temperature is observed using human serum GalTase, in which maximal activity is observed at $30^{\circ} \mathrm{C}$ and complete inhibition is encountered at $40^{\circ} \mathrm{C}$ ( $\mathrm{Kim}$ et al., 1972).

Inhibition studies show that seminal plasma galactosyltransferase is specific for glycosylated nucleotides and that the enzyme has more affinity for di- and triphosphorylated forms of the nucleotides. Monosaccharides do not compete for the active site as they do not inhibit $\left[{ }^{3} \mathrm{H}\right]$ galactose transfer to GlcNAc.

The only known function described for $\alpha$-lactalbumin is to bind GalTase to form a lactose synthetase complex by modifying substrate specificity (Strous, 1986). In a similar manner to the GalTases described in the reproductive tract of the mouse (McLaughlin and Shur, 1987) and rat (Hamilton, 1980) epididymis, human seminal plasma GalTase is also inhibited by $\alpha$-lactalbumin. Both bovine and human $\alpha$-lactalbumin inhibit enzyme activity in a similar manner. This is not surprising since these proteins possess an $85 \%$ homology in their amino acid sequence (Hurley and Schuler, 1987).

The biologically active unit obtained in the radiation inactivation experiments had a molecular mass of $45 \mathrm{kDa}$. This RIS represents the protein core that is necessary for the catalytic activity of the enzyme excluding glycosylation or lipid binding (Beauregard $\mathrm{et}$ al., 1987). It is thus comprehensible to find higher molecular masses from GalTase purification experiments ranging from 43 to $69 \mathrm{kDa}$ with higher molecular masses being characteristic of membrane-bound GalTase, whereas the lower molecular mass forms are found in soluble form (Strous, 1986). The molecular masses of GalTases purified from human serum, amniotic fluid, skin fibroblasts and pleural effusions range between 43 and $55 \mathrm{kDa}$ (Strous, 1986). The soluble GalTase of human milk and colostrum has a molecular mass of $64 \mathrm{kDa}$ (McGuire et al., 1989). The existence of a small biologically active unit of GalTase is also supported by molecular biology studies of a cloned fragment of the human GalTase gene (Aoki et al., 1990). These authors cloned a recombinant form of the human GalTase gene in $E$. coli that produced an active $36 \mathrm{kDa}$ polypeptide and they demonstrated, by site-specific mutagenesis, that residues Tyr284, Tyr309 and Trp310 are responsible for GlcNAc binding while Tyr309 is also implicated in UDP-galactose binding (Aoki et al., 1990).

The site of synthesis and secretion of GalTase in the male reproductive tract is unknown. We present the first evidence that GalTase activity is present in the intraluminal fluid of the human epididymis and that it is low in the proximal caput region and increases to its maximal specific activity in the adjacent downstream segment. This suggests that GalTase may be secreted by the intermediate region of the caput epididymis. However, the activation of a testicular or rete testis inhibited form of the enzyme by the addition of a cofactor or by removal of an inhibitor cannot be ruled out in these experiments. The cytoplasmic droplets are another possible source of GalTase activity. In many species, the cytoplasmic droplet that contains numerous lysosomal enzymes (Garbers et al., 1970; Roberts et al., 1976) slides off the flagellum during epididymal transit (Hermo et al., 1988), although no GalTase activity has been associated with these particles up to the present. However, the samples used in this study are unlikely to contain cytoplasmic droplets since the intraluminal fluid was first centrifuged and subsequently ultracentrifuged to remove particulate matter. In humans, the loss of the cytoplasmic droplet by spermatozoa in the epididymis has not been the subject of extensive research. Bedford et al. (1973) reported that the detachment of the droplet from the flagellum is variable within the human epididymis, and that cytoplasmic droplets are frequently found on caudal spermatozoa. This possible source of GalTase activity thus remains a possibility that warrants further study.

This is the first report concerning the distribution of GalTase activity along the human male reproductive tract. This activity is present in the epididymal lumen and persists in the vas deferens. The presence of such soluble forms of GalTases has also been reported in the male reproductive tracts of rodents. McLaughlin and Shur (1987) identified GalTase in mouse caput epididymal fluid and it is also present in rat rete testis and epididymal fluids (Hamilton, 1981). GalTase activity is also present in cytosolic preparations of male reproductive tract where the activity is associated with epididymal tissues and important sources of activity were described to be of prostatic (rat and mouse) and seminal vesicle (hamster) origin (Reddy et al., 1976). However, these authors reported that prostatic GalTase is membrane bound and is not found in a soluble form. The existence of GalTase activity in human seminal plasma was investigated by Tadolini et al. (1976) who showed that it is not membrane bound and is also present in fluid obtained after prostatic massage; the presence of GalTase activity in epididymal fluids was not studied.

The role of GalTase in the male reproductive tract remains to be elucidated. The importance of sugar moieties in gamete interaction is well documented in mammals (Miller and Ax, 1990) and the acquisition of fertilizing ability in the epididymis 
coincides, in part, with the modification of components on the plasma membrane of spermatozoa (Cooper, 1986; FournierDelpech and Courot, 1987; Eddy, 1988). Thus, it is possible that glycosyltransferases or glycosidases present in the intraluminal fluid are involved in this modification. Accordingly, rat epididymal GalTase can galactosylate a $26 \mathrm{kDa}$ sperm surface protein (Hamilton and Gould, 1982; Hamilton et al., 1986). In humans, galactose residues and a potential acceptor, GlcNAc, are present on the sperm surface (Kallajoki et al., 1985). GlcNAc is bound to human sperm plasma membrane lipids (Kurpisz et al., 1989) which are also suitable GalTase acceptors of galactose (Strous, 1986).

Another interesting fact is that a potential endogenous acceptor of $\left[{ }^{3} \mathrm{H}\right]$ galactose is present in seminal plasma and is lost after ethanol precipitation. Although its nature is unknown, it could be a sugar component such as inositol, present in high quantities in the human reproductive tract, which can act as a substrate in the rat (Hamilton, 1981); glycolipids and glycopeptides are also potential candidates as galactose acceptors (Strous, 1986). Thus, in addition to its potential implication in murine gamete interaction, GalTase may also play a role in rat and mouse sperm maturation in the epididymis. In humans, however, its role remains unknown but further studies appear to be warranted to reveal its implication in some of these processes.

This research was supported by the Medical Research Council of Canada (PG-14) and the Fonds de Recherche en Santé du Québec. The authors would like to thank G. Beauregard for his helpful discussions and Sainte-Justine Hospital for the use of their Gammacell reactor for the irradiation studies and $C$. Boudreault for her assistance in typing this manuscript.

\section{References}

Aarons D, Speake JL and Poirier GR (1984) Evidence for a proteinase inhibitor binding component associated with murine spermatozoa Biology of Reproduction $31811-817$

Aoki D, Appert HE, Johnson D, Wong SS and Fukuda MN (1990) Analysis of the substrate binding sites of human galactosyltransferase by protein engineering EMBO Journal 9 3171-3178

Baumgarten HG, Holstein AF and Rosengren E (1971) Arrangement, ultrastructure, and adrenergic innervation of smooth musculature of the ductuli efferentes, ductus epididymis and ductus deferens of man Zeitschrift für Zellforschung und Mikroskopische Anatomie 120 37-79

Bayna EM, Shaper JH and Shur BD (1988) Temporally specific involvement of cell surface $\beta-1,4$ galactosyltransferase during mouse embryo morula compaction Cell 53 145-157

Beauregard G and Potier M (1982) Radiation inactivation of enzymes at low dose rates: identical molecular weights of rat liver cytosolic and lysosomal neuraminidases Analytical Biochernistry 122 379-384

Beauregard G, Maret A, Salvayre R and Potier M (1987) The radiation inactivation method as a tool to study structure-function relationships in proteins Methods of Biochemical Analysis 32 313-343

Bedford JM, Calvin H and Cooper GW (1973) The maturation of spermatozoa in the human epididymis Joumal of Reproduction and Fertility Supplement 18 199-213

Benau DA and Storey BT (1988) Relationship between two types of mouse sperm surface sites that mediate binding of sperm to the zona pellucida Biology of Reproduction 39 235-244

Bradford MM (1976) A rapid and sensitive method for the quantification of microgram quantities of protein utilizing the principle of protein-dye binding Analytical Biochemistry 72 248-254

Cooper TG (1986) The Epididymis, Sperm Maturation and Fertilisation. SpringerVerlag, Berlin
Eddy EM (1988) The spermatozoon. In The Physiology of Reproduction, Vol 1, pp 27-68 Eds E Knobil and JD Neil. Raven Press, New York

Fayrer-Hosken RA, Caudle AB and Shur BD (1991) Galactosyltransferase activity is restricted to the plasma membranes of equine and bovine sperm Molecular Reproduction and Development 28 74-78

Fournier-Delpech $\mathbf{S}$ and Courot $\mathbf{M}$ (1987) Sperm-zona pellucida binding activity. In Oxford Reviews of Reproductive Biology pp 294-320 Ed. JR Clarke. Clarendon Press, Oxford

Garbers DL, Wakabayashi T and Reed PW (1970) Enzyme profile of the cytoplasmic droplet from bovine epididymal spermatozoa Biology of Reproduction $3327-337$

Hamilton DW (1980) UDP-galactose: $N$-acetylglucosamine galactosyltransferase in fluids from rat testis and epididymis Biology of Reproduction 23 377-385

Hamilton DW (1981) Evidence for $\alpha$-lactalbumin-like activity in reproductive tract fluids of the male rat Biology of Reproduction 25 385-392

Hamilton DW and Gould RP (1982) Preliminary observations on enzymatic galactosylation of glycoproteins on the surface of rat caput epididymal spermatozoa International Journal of Andrology (Supplement) 5 73-80

Hamilton DW, Wenstrom JC and Baker JB (1986) Membrane glycoproteins from spermatozoa: partial characterization of an integral $M_{r}=24000$ molecule from rat spermatozoa that is glycosylated during epididymal maturation Biology of Reproduction 34 925-936

Hermo L, Dworkin J and Oko R (1988) Role of epithelial clear cells of the rat epididymis in the disposal of the contents of cytoplasmic droplets detached from spermatozoa American Journal of Anatomy 183 107-124

Humphreys-Beher MG and Blackwell RE (1989) Identification of a deoxyribonucleic acid allelic variant for $\beta$ I-4 galactosyltransferase expression associated with male sperm binding/penetration infertility American joumal of Obstetrics and Gynecology 160 1160-1165

Humphreys-Beher MG, Garrison PW and Blackwell RE (1990) Detection of antigalactosyltransferase antibodies in plasma from patients with antisperm antibodies Fertility and Sterility 54 133-137

Hurley WL and Schuler LA (1987) Molecular cloning and nucleotide sequence of a bovine $\alpha$-lactalbumin cDNA Gene 61 119-122

Kallajoki M, Malmi R, Virtanen I and Suominen J (1985) Glycoconjugates of human sperm surface: a study with fluorescent lectin conjugates and lens culinaris agglutinin affinity chromatography Cell Biology International Reports 9 151-164

Kepner GR and Macey RI (1968) Membrane enzyme systems: molecular size determinations by radiation inactivation Biochimica et Biophysica Acta 163 188-203

Kim YS, Perdomo J and Whitehead JS (1972) Galactosyltransferase in human blood Joumal of Clinical Investigation 51 2024-2032

Kurpisz M, Clark GF, Mahony M, Anderson TL and Alexander NJ (1989) Mouse monoclonal antibodies against human sperm: evidence for immunodominant glycosylated antigenic sites Clinical and Experimental Immunology $\mathbf{7 8}$ 250-255

Langlais J, Zollinger M, Plante L, Chapdelaine A, Bleau G and Roberts KD (1981) Localization of cholesteryl sulfate in human spermatozoa in support of a hypothesis for the mechanism of capacitation Proceedings of the National Academy of Sciences USA 78 7266-7270

Lea DE (1955) Actions of Radiations on Living Cells (2nd edn) pp 69-99. Cambridge University Press, Cambridge

Lopez LC, Bayna EM, Litoff D, Shaper NL, Shaper JH and Shur BD (1985) Receptor function of mouse sperm surface galactosyltransferase during fertilization Joumal of Cell Biology 101 1501-1510

Macek MB and Shur BD (1988) Protein-carbohydrate complementarity in mammalian gamete recognition Gamete Research 20 93-109

McGuire EJ, Kerlin R, Cebra JL and Roth S (1989) A human milk galactosyltransferase is specific for secreted, but not plasma, IgA Joumal of Immunology 143 2933-2938

McLaughlin JD and Shur BD (1987) Binding of caput epididymal mouse sperm to the zona pellucida Developmental Biology 124 557-561

Miller DJ and Ax RL (1990) Carbohydrates and fertilization in animals Molecular Reproduction and Development 26 184-198

Miller DJ, Cross NL, Vasquez-Levin M and Shur BD (1992) The role of sperm galactosyltransferase in fertilization: presence and possible function in humans and other mammals. In Comparative Spermatology - 20 Years After pp 569-574 Ed. B Bacetti. Raven Press, NY

Passaniti A and Hart GW (1990) Metastasis-associated murine melanoma cell surface galactosyltransferase: characterization of enzyme activity and identification of the major surface substrates Cancer Research 50 7261-7271 
Penno MB, Passaniti A, Fridman R, Hart GW, Jordan C, Kumar S and Scott AF (1989) In vitro galactosylation of a 110-kDa glycoprotein by an endogenous cell surface galactosyl-transferase correlates with the invasiveness of adrenal carcinoma cells Proceedings of the National Academy of Science USA 86 6057-6061

Ram PA, Fung M, Millette CF and Armant DR (1989) Thin-layer chromatographic method for the determination of glycosyltransferase activity Analytical Biochemistry $178421-426$

Reddy PRK, Tadolini B, Wilson J and Williams-Ashman HG (1976) Glycoprotein glycosyltransferases in male reproductive organs and their hormonal regulation Molecular and Cellular Endocrinology 5 23-31

Roberts ML, Scouten WH and Nyquist SE (1976) Isolation and characterization of the cytoplasmic droplet in the rat Biology of Reproduction 14 421-424

Runyan RB, Maxwell GD and Shur BD (1986) Evidence for a novel enzymatic mechanism of neural crest cell migration on extracellular glycoconjugate matrices Joumal of Cellular Biology 102 432-441

Scully NF, Shaper JH and Shur BD (1987) Spatial and temporal expression of surface galactosyltransferase during mouse spermatogenesis and epididymal maturation Developmental Biology 124 111-124
Shur BD (1984) The receptor function of galactosyltransferase during cellular interactions Molecular and Cellular Biochemistry 61 143-158

Shur BD and Neely CA (1988) Plasma membrane association, purification, and partial characterization of mouse sperm $\beta$ 1,4-galactosyltransferase Journal of Biological Chemistry 26317 706-17 714

Strous GJ (1986) Golgi and secreted galactosyltransferase. In Critical Reviews in Biochemistry, Vol. 21, no. 2, pp 119-151. CRC Press

Sullivan R, Ross P and Bérubé B (1989) Immunodetectable galactosyltransferase is associated only with human spermatozoa of high buoyant density Biochemical and Biophysical Research Communications 163184

Tadolini B, Wilson J, Reddy PRK and Williams-Ashman HG (1976) Characteristics and hormonal control of some glycoprotein glycosyltransferase reactions in male reproductive organs Advances in Enzyme Regulation 15 319-336

Tulsiani DRP, Skudlarek MD and Orgebin-Crist M-C (1990) Human sperm plasma membranes possess $\alpha$-D-mannosidase activity but no galactosyltransferase activity Biology of Reproduction 42 843-858 